Essay

\title{
Death Row Confessions and the Last Meal Test of Innocence
}

\section{Kevin M. Kniffin * and Brian Wansink}

Dyson School of Applied Economics and Management, Cornell University, Warren Hall, Ithaca, NY 14853, USA; E-Mail: bcw28@cornell.edu

* Author to whom correspondence should be addressed; E-Mail: kmk276@cornell.edu; Tel.: +1-607-254-4960.

Received: 28 October 2013; in revised form: 23 November 2013 / Accepted: 20 December 2013 / Published: 30 December 2013

\begin{abstract}
Post hoc analyses of Rector v. Arkansas have regularly highlighted that the defendant requested that part of his last meal be saved so that he could it eat later. While the observation is typically raised as part of arguments that Rector was incompetent and unfit for execution, the more basic fact is that commentators have drawn important inferences about Rector's mental state from how he treated his last meal. In this essay, we draw upon multiple disciplines in order to apply the same inferential logic to a much broader sample and explore the question of whether traditionally customized last meals might offer signals of defendants' guilt or innocence. To investigate this, the content of last-meal requests and last words reported for people executed in the United States during a recent five-year period were examined. Consistent with the idea that declination of the last meal is equivalent to a signal of (self-perceived) innocence, those who denied guilt were 2.7 times as likely to decline a last meal than people who admitted guilt ( $29 \%$ versus $8 \%$ ). Consistent with the complementary theory that people who admit guilt are relatively more "at peace" with their sentence, these individuals requested $34 \%$ more calories of food than the rest of the sample (2786 versus 2085 calories). A third finding is that those who denied guilt also tended to eat significantly fewer brand-name food items. Previous discussions of last meals have often lacked quantitative measurements; however, this systematic analysis shows that last meal requests offer windows into self-perceived or self-proclaimed innocence. Knowing one's last meal request and one's last words can provide valuable new variables for retrospectively assessing the processes that led to past executions.
\end{abstract}


Keywords: capital punishment; death penalty; last meals; last words; eating; food; traditions; execution; innocent; guilty

\section{Introduction}

The execution of Rickie Ray Rector by the State of Arkansas on January 24, 1992, drew an extraordinary amount of attention, partly due to its relevance for then-Governor Bill Clinton's bid for the Presidency and partly due to claims that Rector was incompetent [1]. Originally sentenced to death on November 11, 1982, for his murder of a police officer in 1981, Rector shot himself in the forehead in the moments after killing the officer and, consequently, endured injuries that required surgical repair [2]. After a number of appeals, the United States Supreme Court ultimately denied a hearing on June 24, 1991, with Justice Marshall dissenting on: (a) the principle of his opposition to the death penalty in all cases as "cruel and unusual punishment"; and, independently, (b) his opinion in this case that Rector was incompetent as a result of the "frontal lobotomy" that he received in the wake of his self-inflicted gunshot wound [3].

One aspect of Rector's execution that continues to draw popular attention - from people who are opposed to the death penalty and others who appear to be fascinated by last meals - is that Rector did not eat the pecan pie that he was served as part of his last meal and, instead, reportedly expected to eat the rest of it after the execution [4,5]. While Rector's treatment of the pecan pie does not appear to have been considered by any aspect of the judicial process prior to Rector's execution, the anecdotal account of his last meal has been repeated and discussed in a wide array of domains.

Focusing on law reviews, for example, in Campbell's commentary about how competency should be assessed and managed in relation to the death penalty, she introduces her argument with the pecan pie account and writes about Rector that "clearly he was a man who did not understand his fate" [6]. Cottrol notes Rector's pecan pie after acknowledging that he opposes capital punishment and laments that the death penalty "has become a macabre prop for those seeking office" [7]. Rapoport notes the pecan pie in the context of asserting - as a matter of interpretation, not a matter of reporting - that then-Governor Clinton "believed clemency was warranted but nevertheless chose not to grant" it due to perceptions that "the political price would prove too high" [8]. Additionally and not exhaustively, Bright notes Rector's dessert in the context of lamenting "the politicizing of the death penalty" [9].

Most generally, the implication of these observations is that people have considered Rector's treatment of his last meal to have significant relevance for their post hoc analysis of his execution. The intersection of legal scholarship and food in these analyses merits a closer integration of multidisciplinary research concerning food consumption. In fact, a more basic connection between last meals and executions has been publicly advanced that also warrants attention. Specifically, in their unsystematic review of last meals from around the world, Bigert and Bergstrom assert that there is a connection between the declination of a last meal and whether or not a person's guilt has been posthumously disputed and challenged [10]. The common thread that is found in discussions about Rector and the assertion by Bigert and Bergstrom is that last meals function to signal the legitimacy of an execution. 
To date, no formal or informal appeals (e.g., for a stay of execution) appear to have been made in the United States on the basis of a person's declination of the last meal; however, we present a systematic analysis in this essay to help identify and interpret any signals that might be provided by last meals. Our analysis complements Brisman's study of food in prisons in which he argues generally and descriptively that "food is a particularly useful lens through which to investigate power relations in prison" [11]. In our case, while previous research concerning the legitimacy of the death penalty has focused on variables, such as the influence of gender, ethnic and religious biases on jury decisions [12-14], we focus on details related to last meals and last words. Most specifically, we ask whether a purportedly innocent condemned person is less likely to accept a last meal, and if they do, how does their meal differ from a person who has confessed guilt?

If support exists for the notion that declination of the last meal constitutes a de facto innocence test, then people with authority to issue late-hour stays of execution would properly consider the variable as part of their deliberations; and, one expects, last meals would then be more frequently declined as a means of seeking to avoid execution. If systematic analysis rejects the notion that declination of last meals is more common among people who claim innocence, then it becomes fair to infer that the acceptance of last meals does not provide any additional measure of guilt for the person facing execution. Independent from any prospective impact of the analysis that we present, the current essay does test a question that has relevance for those working to retrospectively assess guilt among people who have been executed in the past [15].

\section{The Ritual and Reward of Last Meals}

All of the processes relating to the death penalty involve important ritualistic aspects, and the tradition of allocating last meals is among the most prominent [16]. The reasons for the tradition include spiritual notions (in some parts of the world, historically) that the meal will provide "safe passage to the land of the dead" for the person being executed [17]. Reasons for continuation of the tradition that do not involve spiritual references include the idea that it is part of the diffusion of responsibility that exists among the people who work as executioners to help them disavow personal responsibility for their actions [18]. Among people who oppose the death penalty, there are critics who argue that the tradition of last meals, as well as the popular discussion of last meals, trivializes the subsequent execution. In contrast, Meyer contends that "The symbolism of the last-meal ritual is perhaps even richer and more multivocal than the ritual of last words" [19].

Perhaps because of the deeply ritualistic and morbid nature of the topic, there have, until recently, been no systematic analyses conducted of the content of last meals. As Wansink, Kniffin and Shimizu [20] highlight in their systematic analysis of the last meals of people who were executed in the United States between 2002 and 2006, there is a long history of popular fascination with individual last meals; however, the calculation of aggregate patterns seems to have been taboo. Among the findings of their analysis, people facing execution tend to select calorically rich meals that feature "comfort foods" that are high in carbohydrates and commonly consumed by people facing stressful situations. They also, notably, find that last meals were either not requested or reported for 51 of the 247 people (21\%) who were executed during that period in the United States. Most generally, these findings are consistent with previous research that demonstrates that significantly more modest forms 
of stress and social exclusion, which is shown at its extreme on death row, can influence people to eat increased amounts of comfort food [21,22].

\section{Hypothesis}

Even with the knowledge of what others have chosen for their last meals, predicting what a person would eat in the extraordinarily artificial environment of death row is not a simple task. On the one hand, if the last meal presents one more, likely final, opportunity to engage in an enjoyable sensory experience, then the selection and consumption of food and beverages, particularly so-called comfort food, in the face of the death penalty becomes more understandable. Likewise, if a person has full faith that they will be greeted after their death with rewards in the afterlife, then that would be another reason to expect consumption of a relatively large last supper, since the meal would not be eaten with the incredibly foreboding expectation of death [23]. In such a scenario, the meals would arguably be expected to be comparable to the meals that people in any other circumstance (i.e., away from death row) would imagine to be ideal last meals [20].

On the other hand, given an expectation that people would either fight or take flight in the face of the imminent threat posed by execution, it is reasonable to anticipate that anyone facing the death penalty would decline a last meal as a function of terror. More specifically, if a person has been wrongfully convicted of the crime(s) for which the death sentence was issued, it is also reasonable to anticipate that such a person would be so enraged with anger that they would refuse the most ritualistic "trapping" of execution, the last meal.

The principal focus of this research is to examine if individuals who deny their guilt are more likely to decline a last meal or to request fewer calories of such a meal. A secondary focus is to examine the hypothesis generated by Bigert and Bergstrom's claim that "executed people whose guilt was later strongly called into question" typically "chose to decline their Last Supper" [10]. With both of these predictions, the theory presumes that imperfections in the criminal justice system can permit the wrongful execution of people and considers whether or not the consumption or denial of a last meal constitutes a de facto innocence test. Estimates of the number of people who have been sentenced and executed for crimes for which they were wrongfully convicted do not exist; however, our analysis presumes that to be plausible. Consistent with this approach, Westervelt and Cook note that 138 people in the United States have been "exonerated of capital crimes and released from death row" prior to any scheduled execution between 1973 and November, 2011 [24].

\section{Methods}

We built upon a database described by Wansink et al. of 247 people who were executed in the United States between 2002 and 2006 to analyze relationships between last meal requests and claims to innocence [20]. Because of the variable reporting of executions [25], two recodings of execution records were made. First, we recoded the acceptance or declination of last meals by applying a more conservative standard to assessing whether last meals were declined. Whereas the original dataset assumed that the absence of reporting about a last meal indicated that it was declined, our categorization of "did not eat" required an explicit report that the person declined the traditional last meal. 
Second, as a measure of one's claim to innocence or guilt, we analyzed the last words that people uttered when asked in the execution chamber if they had any last words [16]. Our collection of last words is based upon reports provided by state court systems and published through newspaper accounts. While executions receive varied amounts of national news coverage [25,26], our database triangulated: (1) existing local or regional news articles; (2) any national news coverage; and (3) official records published by state corrections departments. We rely on the last words as measures of innocence with the full understanding that they are not necessarily true; however, one would expect (and it is an assumption in our analyses) that anyone who might be innocent would indeed protest their wrongful execution. To highlight our understanding, we can note that none of the people who were executed during the recent five-year period that we studied have yet to be posthumously exonerated.

We coded last words according to whether the person: (1) denied guilt; (2) admitted guilt or apologized; or (3) made a minimalist statement in which they neither denied nor admitted guilt and either declined to speak or said "No, thank you", "Absolutely not" or "No, let's get this over with; let's do it." For additional descriptive information, we also coded last words with respect to whether they invoked religious references (e.g., to the afterlife) or "love", since those were common and measurable themes. Our coding is similar to the approach that Meyer [19] employed; however, our categories are more coarsely grained, partly because, while Meyer's focus on last words in the State of Texas permitted full-text analysis for each person, our multi-state analysis is based upon multiple sources, such as news reports, that provide variable amounts of information. The themes that we coded are also consistent with the qualitative analysis of last words that Barker completed [27]. Following Leistico et al.'s protocol [28], two raters without knowledge of our hypothesis coded the last words with respect to denial or admittance of guilt, with solid measures of inter-rater reliability $(\alpha=0.94$ for denial of guilt, $\alpha=0.77$ for admission of guilt), and discussions among the raters resolved any discrepancies.

\section{Results}

After content analyzing the last words of the people in the sample, 10\% (24 of the 247) denied guilt, $21 \%$ (53 of 247) made no statement or a minimalist response and $22 \%$ (60 of 247) apologized or admitted guilt (see Table 1). A second level of analysis revealed 35\% (86 of 247) of the last words included a religious reference (e.g., to God, heaven or Allah) and 28\% (70 of 247) invoked the word "love."

Table 1. Common themes in last words (percentages within columns).

\begin{tabular}{ccccc}
\hline & $\begin{array}{c}\mathbf{N} \\
\text { (Total of 247) }\end{array}$ & $\begin{array}{c}\text { Made References } \\
\text { to Religion } \\
\text { (N = 85) }\end{array}$ & $\begin{array}{c}\text { Made } \\
\text { References to } \\
\text { Love (N = 69) }\end{array}$ & $\begin{array}{c}\text { No } \\
\text { Last Words (N = 53) }\end{array}$ \\
\hline $\begin{array}{c}\text { Individuals Who } \\
\text { Denied Guilt } \\
\text { Individuals Who } \\
\text { Neither Denied } \\
\text { Nor Admitted }\end{array}$ & $24(10 \%)$ & $7(8 \%)$ & $5(7 \%)$ & $0(0 \%)$ \\
$\begin{array}{c}\text { Individuals Who } \\
\text { Admitted Guilt }\end{array}$ & $60(25 \%)$ & $32(38 \%)$ & $43(62 \%)$ & $53(100 \%)$ \\
\hline
\end{tabular}


To examine the hypothesis that the declination of last meals (a decision made by $15 \%$ of the sample (38 of 247)) is more likely by people who report their innocence, an ANOVA was conducted to compare those who denied guilt in their last words with the rest of the sample and found a significant difference $(F=3.91, p<0.01)$, whereby deniers tended to eat significantly less frequently ( $71 \%$ of the people) than people who apologized for the crimes for which they were sentenced ( $92 \%$ of the people). A consistent and complementary trend illustrated in Figure 1 exists for the estimated number of calories, whereby people who admit guilt tend to eat significantly larger meals, with an average of 2786 calories, than the rest of the sample, whose meals tended to be 2,085 calories $(F=4.31, p<0.05)$.

Among those people who invoked love or religion, it is notable that these sentiments correlate with apologies $(r=0.13, p<0.05 ; r=0.22, p<0.01)$. It is important to note, however, that there is no significant relationship between these invocations and whether they denied guilt or whether they ate a last meal. This absence of significant correlations between expressions of love and religion and whether a person denies guilt or declines a last meal is consistent with expectations. This is important, because it counters the possibility that religious faith, for example, might spuriously account for the main findings in Figure 1.

Figure 1. How self-reported guilt relates to last meal requests.

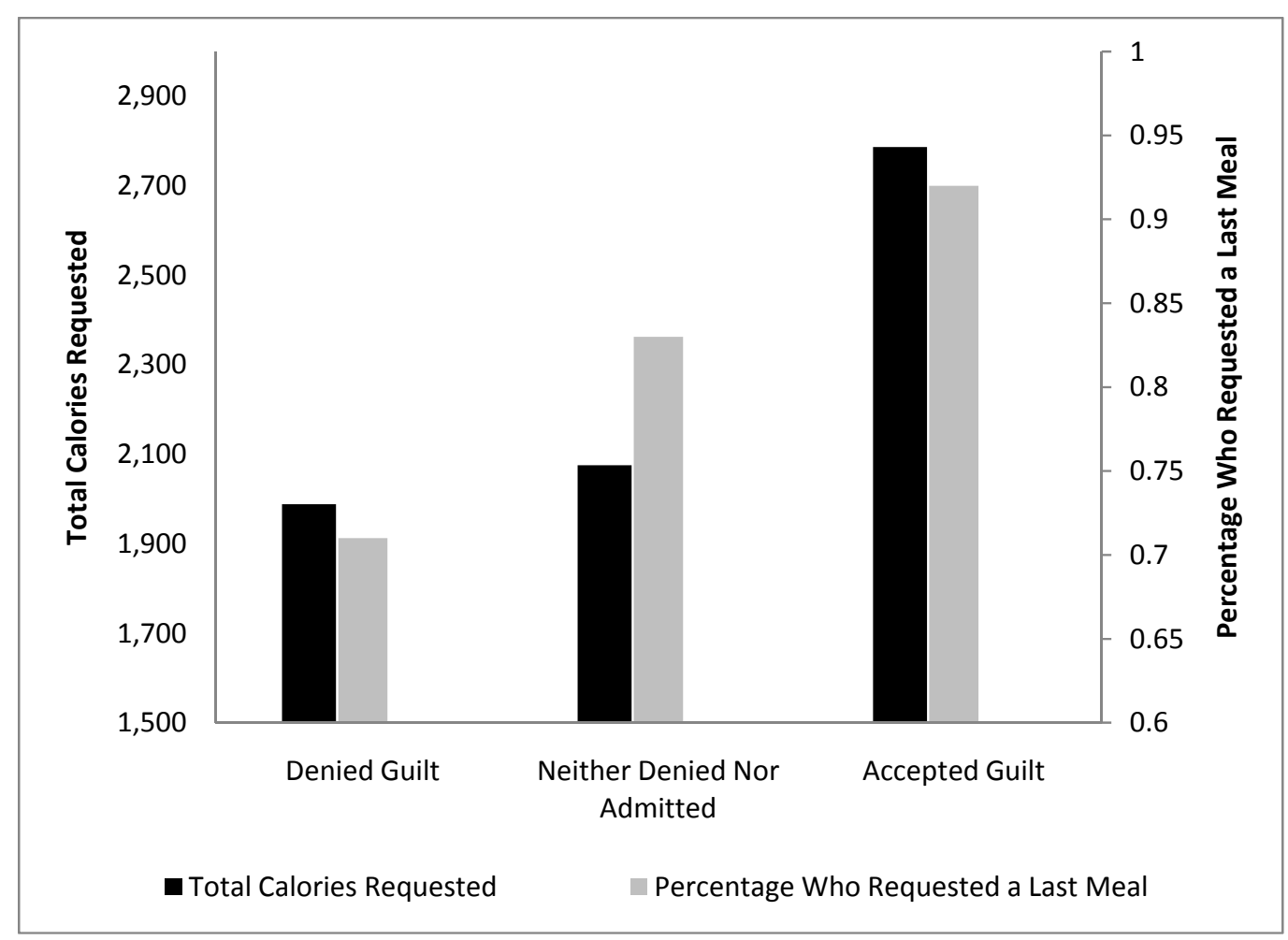

In order to assess whether there are finer-grained signals that exist (in the selection of last meals) that help indicate whether someone perceives that they are innocent or not, we examined the specific food types that were requested by those who denied guilt. Notably, we find that people who denied guilt selected significantly fewer brand-name items $(F=4.11, p<0.05)$, with an average of 0.18 
brand-name items among 17 people who denied guilt and an average of 0.56 items among 171 others for whom we have information.

\section{Discussion}

Presuming, for the sake of analysis, that people who claim to be innocent are innocent, our findings support the principal hypothesis that those who are innocent are more likely to either decline a last meal or to request a less indulgent (a less caloric) meal than those who admit guilt. That is, those who denied guilt were 2.7 times as likely to decline a last meal than people who admitted guilt (29\% versus $8 \%$ ), whereas those who admitted guilt requested $34 \%$ more calories of food than the rest of the sample (2,786 versus 2,085 calories). Although this is a robust general finding, the relatively small number of people who denied guilt does not enable a more fine-grained comparison across demographic traits, such as age, ethnicity or region. Generally, though, Bigert and Bergstrom's claim that innocent people turn down their last meal is overstated. The majority of those claiming innocence-71\% - still asked for a last meal. They were less likely to request a meal; and, they requested less calories, but the majority still wanted to eat.

With respect to potential explanations for our main findings, Elias Syriani, who denied guilt for the crime for which he was sentenced, reportedly said "I want no meal from this place" in his last words in 2005 [10]. To the extent that agreement to accept the traditional invitation of a last meal implies some consent to the execution process, it is sensible that people who deny guilt will tend to deny the invitation to a last meal.

With regard to the caloric content of the meals, a video-recorded jailhouse interview with Marion Pruett shows him, prior to being executed for crimes for which he apologized, describing the extravagant, high-calorie meal that he was planning to request for his last meal. For his explanation, he specified that "I've made my peace" [10], implying that his acceptance of his guilt and possibly his sentence permitted him to enjoy a final meal. In the interview, in fact, Pruett and a number of the attending prison guards chuckled at the thought of the feast that he was describing.

Concerning the finding that brand-name foods are selected with significantly less frequency among those who deny guilt, the pattern makes sense in light of Wansink et al.'s analysis that brand-name items constitute a kind of "comfort food" [20]. More specifically, people who are facing an execution for which they claim innocence appear to lack an appetite when compared with the rest of the sample whereas people who have accepted guilt appear relatively more "comfortable" (cf. Pruett's statement that he has "made [his] peace").

An overmerited implication of these findings would be to consider whether appellate judges and governors should give extra consideration to last-minute appeals from people who declined the last meal. In addition to rejecting the strong form of the hypothesis that the declination of last meals is an indicator of self-reported innocence, there are several limitations to generalizing from our analysis. Most notably, our use of claims to innocence needs to be understood clearly, since the claims might or might not be viewed honestly by the person making the statement. An organization that is committed to highlighting "the incredible flaws that underpin America's death penalty" - the Death Penalty Information Center (DPIC) - identifies 10 people among the group of more than 1,000 people who have been executed in the United States since 1976 as "executed but possibly innocent" [29]. Of their 
group of 10, one person was part of the sample that we considered; consequently, it is worth recognizing that the DPIC, at least, does not presently recognize the great majority of claims to innocence that our study considered as having "strong evidence of innocence." Nevertheless, it is also worth recognizing that our findings do have relevance for understanding claims to innocence in addition to the fact that the current absence of evidence in support of innocence does not preclude the possibility that exculpatory evidence exists in some undiscovered way for any number of the people in our sample.

\section{Conclusions}

Most generally, the idea that meals can signify more than simply the consumption of calories is not novel outside of the context of last meals on death row. In fact, in regular circumstances, it is easy to recognize special holiday feasts, such as Thanksgiving [30], or meals between romantic partners [31-33] as examples in which eating has significance beyond the specifics of what is being consumed. In that context, the idea that the preferences displayed through last meals might signify something beyond a person's physiological taste preferences is predictable and consistent. The social meanings that are commonly attached to food also presumably help to explain why post hoc analyses of Rector continue to note the defendant's treatment of his pecan pie.

Similar to how the death penalty elicits debate and argument [34] and is variably used in countries across the world [35,36], the practice of inviting last meal requests tends to provoke an independent set of debates; and, a person's position on the two practices are not necessarily aligned. In Texas, for example, the State recently took action to discontinue the tradition of last meals on the argument that the traditional practice is unnecessary and wasteful [37,38] after Lawrence Russell Brewer "parodied" the practice by ordering an extraordinary amount of food and eating none of it before his execution for the "racially-motivated dragging death of James Byrd, Jr." [39]. While it is outside of the scope of our analysis to consider the myriad ritualistic functions of last meals, the elimination of the last meal tradition, in light of our findings, would also eliminate one of the few channels of communication that have traditionally existed for people facing execution. In the case of Rector, for example, the absence

of a last meal would have removed a dimension of analysis that many serious observers have considered to be important.

As with the other anomalies that we referenced in our Introduction concerning disproportionate ways in which traits, such as gender, ethnicity and religion, can unduly influence aspects of the criminal justice system related to the death penalty, the patterns that we test and find with respect to last meals contribute another potential signal for understanding how individuals perceive their innocence in the face of execution. It is possible these findings could influence future considerations involving executions; perhaps, they might encourage the denial of a last meal or, perhaps, they might tip the scales of justice in favor of a stay of execution for someone who declines their invitation to a last meal. While that possibility exists for any cue that researchers find with respect to anomalous influences into criminal justice processes, our findings should be most useful for understanding and assessing the innocence and perceived innocence of people who have been executed in the past. 


\section{Acknowledgments}

The authors are grateful for constructive feedback on an earlier version of the manuscript from Leona Jochnowitz and several anonymous reviewers. The authors are grateful for research assistance from Adam Brumberg, Nishtha Ghosh, Katherine Hoy, Kale Smith and Mitsuru Shimizu. The authors are also grateful for helpful communications with Owen Jones and Craig Wansink with the standard disclaimer that any errors of commission or omission are ours. This study was approved by the Cornell University Institutional Review Board and was not funded by any governmental or non-governmental grant. This study was self-funded.

\section{Conflicts of Interest}

The authors declare no conflict of interest.

\section{References}

1. Hugh Aynesworth. "Execution in Arkansas draws Clinton to state." The Washington Times, 24 January 1992.

2. Rector v. Arkansas, 727 F. Supp. 1285 (E. D. Ark. 1990).

3. Rector v. Arkansas, 501 U.S. 1239 (1991). 111 S.Ct. 2872, 115 L.Ed.2d 1038. http://www.law.cornell.edu/supremecourt/text/501/1239.

4. Sharon LaFraniere. "Governor's camp feels his record on crime can stand the heat." The Washington Post, 5 October 1992, p. A6.

5. William Booth. "Courts' death row quandary: How crazy is too crazy to die?" The Washington Post, 5 May 1998, p. A3.

6. Melinda S. Campbell. "Sell, singleton, and forcible medication-running roughshod over liberty." University of Toledo Law Review 35 (2004): 691.

7. Robert J. Cottrol. "Submission is not the answer: Lethal violence, microcultures of criminal violence and the right to self-defense." University of Colorado Law Review 69 (1998): 1029. http://www.saf.org/lawreviews/cottrol1.html.

8. Elizabeth Rapaport. "Straight is the gate: Capital clemency in the United States From Gregg to Atkins.” New Mexico Law Review 33 (2003): 349-63.

9. Stephen B. Bright. "Advocate in residence: The death penalty as the answer to crime: Costly, counterproductive and corrupting." Santa Clara Law Review 36 (1996): 1069-71.

10. Mats Bigert, and Lars Bergstrom. Last Supper [documentary]. Stockholm: Bigert \& Bergstrom, 2005.

11. Avi Brisman. "Fair fare?: Food as contested Terrain in U.S. Prisons and Jails." Georgetown Journal on Poverty Law and Policy 15 (2008): 49-50.

12. Mona Lynch, and Craig Haney. "Discrimination and instructional comprehension: Guided discretion, racial bias, and the death penalty." Law \& Human Behavior 24 (2000): 337.

13. Monica K. Miller, and Brian H. Bornstein. "The use of religion in death penalty sentencing trials." Law \& Human Behavior 30 (2006): 675.

14. Monica K. Miller, and Brian H. Hayward. "Religious characteristics and the death penalty." Law \& Human Behavior 32 (2008): 113. 
15. Barry Scheck, Peter Neufield, and Jim Dwyer. "Actual Innocence: When justice goes wrong and how to make it right (2003)." Jurimetrics 42 (2002): 221.

16. Daniel LaChance. "Last words, last meals, and last stands: Agency and individuality in the modern execution process." Law \& Social Inquiry 32 (2007): 701.

17. LuAnne Ruth. "Review of Last Supper." Journal of American Folklore 124 (2011): 105-07.

18. Michael J. Osofsky, Albert Bandura, and Philip G. Zimbardo. "The role of moral disengagement in the execution process.” Law \& Human Behavior 29 (2005): 371.

19. Linda Ross Meyer. "The Meaning of Death: Last Words, Last Meals." In Who Deserves to Die: Constructing the Executable Subject. Edited by Austin Sarat and Karl Shoemaker. Amherst: University of Massachusetts Press, 2011, pp. 176-206.

20. Brian Wansink, Kevin M. Kniffin, and Mitsuru Shimizu. "Death row nutrition: Curious conclusions to last meals." Appetite 59 (2012): 837.

21. Chen-Bo Zhong, and Geoffrey J. Leonardelli. "Cold and lonely: Does social exclusion literally feel cold?" Psychological Science 19 (2008): 838-42.

22. Brian Wansink, Ying Cao, Prerna Saini, Mitsuru Shimizu, and David R. Just. "College cafeteria snack food purchases become less healthy with each passing week of the semester." Public Health Nutrition 16 (2013): 1291-95.

23. Brian Wansink, and Craig Wansink. "The largest last supper: Depictions of food portions and plate size increased over the millennium.” International Journal of Obesity 34 (2010): 943.

24. Saundra D. Westervelt, and Kimberly J. Cook. Life After Death Row: Exonerees' Search for Community and Identity. New Brunswick: Rutgers University Press, 2012.

25. Andrew Hochstetler. "Reporting of executions in U. S. Newspapers." Journal of Crime and Justice 24 (2001): 1.

26. Kevin F. O'Neill. "Muzzling death row inmates: Applying the first amendment to regulations that restrict a condemned prisoner's last words.” Arizona State Law Journal 33 (2001): 1159.

27. Vanessa Barker. "Last Words: Structuring the State's Power to Punish." In Who Deserves to Die: Constructing the Executable Subject. Edited by Austin Sarat and Karl Shoemaker. Amherst: University of Massachusetts Press, 2011, pp. 151-75.

28. Anne-Marie R. Leistico, Randall T. Salekin, Jamie DeCoster, and Richard Rogers. "A large-scale meta analysis relating the hare measures of psychopathy to antisocial conduct." Law \& Human Behavior 32 (2008): 28.

29. Death Penalty Information Center (DPIC). Executed But Possibly Innocent. Available online: http: |lwww.deathpenaltyinfo.org/executed-possibly-innocent (accessed on 25 October 2013).

30. Melanie Wallendorf, and Eric J. Arnould. "We gather together': Consumption rituals of Thanksgiving day.” Journal of Consumer Research 18 (1991): 13.

31. Kevin M. Kniffin, and Brian Wansink. "It's not just lunch: Extra-pair commensality can trigger sexual jealousy." PLoS One 7 (2012): e40445.

32. Caron F. Bove, Jeffery Sobal, and Barbara S. Rauschenbach. "Food choices among newly married couples: Convergence, conflict, individualism, and projects." Appetite 40 (2003): 25-41.

33. Lisa Miller, Paul Rozin, and Alan Page Fiske. "Food sharing and feeding another person suggest intimacy: Two studies of American college students.” European Journal of Social Psychology 28 (1998): 423-36. 
34. John D. Bessler. "Tinkering around the edges: The supreme court's death penalty jurisprudence." American Criminal Law Review 49 (2012): 1913.

35. Yingyos Leechaiana, and Dennis R. Longmire. "The use of the death penalty for drug trafficking in the United States, Singapore, Malaysia, Indonesia, and Thailand: A comparative legal analysis." Laws 2 (2013): 115-49.

36. James Michael Olivero. "The imposition of the death penalty on mexican nationals in the United States and the Cultural, Legal, and Political Context." Laws 2 (2013): 33-50.

37. Manny Fernandez. "Texas death row kitchen cooks its last 'Last Meal." The New York Times, 23 September 2011, p. A17.

38. Kameel Stanley. "Last meal a staple for death row inmates." St. Petersburg Times, 11 October 2011, p. B1.

39. Leona D. Jochnowitz. "Review of Who Deserves to Die." Criminal Justice Review 37 (2012): 535-37.

(C) 2013 by the authors; licensee MDPI, Basel, Switzerland. This article is an open access article distributed under the terms and conditions of the Creative Commons Attribution license (http://creativecommons.org/licenses/by/3.0/). 